\title{
The effect of preserving antral innervation and of a pyloroplasty on gastric emptying after vagotomy in man
}

\author{
R. J. CLARKE ${ }^{1}$ AND J. ALEXANDER-WILliams ${ }^{2}$ \\ From the General Hospital, Birmingham
}

SUMMARY A prospective randomized trial of 40 duodenal ulcer patients is reviewed. The patients had one of four operations (selective vagotomy, proximal gastric vagotomy, selective vagotomy plus pyloroplasty, or proximal gastric vagotomy plus pyloroplasty). The gastric emptying of a hypertonic fluid meal was assessed before and three to four months after operation. Selective vagotomy without a drainage procedure results in gastric retention and should no longer be considered as a method of treatment for duodenal ulcer. Proximal gastric vagotomy without a drainage procedure does not lead to gastric retention. Initial gastric emptying is more rapid after proximal gastric vagotomy but the final emptying time is the same as before operation and this operation alters the pattern of gastric emptying less than the other operations. Pyloroplasty added to either selective or proximal gastric vagotomy results in loss of the normal regulation of gastric emptying, very rapid initial gastric emptying, and a significant increase in the incidence of 'dumping'. It appears from these studies that 'dumping' is due to rapid gastric emptying and mainly due to the drainage procedure.

Vagotomy combined with a drainage procedure is now established as the elective method of treatment for duodenal ulceration by the majority of surgeons in Britain. However, over the last 15 years it has become increasingly clear that some patients develop sequelae, such as diarrhoea, 'dumping', or vomiting, which seem to be directly related to the operation (Goligher, Pulvertaft, Irvin, Johnston, Walker, Hall, Willson-Pepper, and Matheson, 1972).

Amdrup and Jensen (1970) and Johnston and Wilkinson (1970) suggested that these sequelae could be minimized or abolished by performing a proximal gastric vagotomy without a drainage procedure. (Synonyms are highly selective vagotomy, parietal cell vagotomy, selective proximal vagotomy.) Proximal gastric vagotomy denervates the acidsecreting area of the stomach but preserves the innervation to the gastric antrum.

Burge, MacLean, Stedeford, Pinn, and Hollanders (1969) suggested that a drainage procedure was not necessary with selective vagotomy in the absence of duodenal stenosis.

A randomized trial of proximal gastric vagotomy

'Present address: District General Hospital, Yeovil, Somerset.

'Requests for reprints to Mr J. Alexander-Williams, General Hospital, Birmingham B4 6NH.

Received for publication 12 January 1973. and selective vagotomy was planned to assess the effect of preserving antral innervation and of pyloroplasty on gastric emptying in man.

\section{Materials and Methods}

Forty consecutive male patients with uncomplicated duodenal ulcers were included in the trial. No patient was excluded because of obesity. All patients had unequivocal evidence of a duodenal ulcer on barium meal examination and at operation.

The first 20 patients in the trial were treated by proximal gastric vagotomy or selective vagotomy without a drainage procedure; the only difference between the two operations was the presence or absence of antral innervation. Because of gastric stasis in patients with a selective vagotomy (Clarke, McFarland, and Williams, 1972b) a pyloroplasty was included in all operations on the second 20 patients in the trial. The pyloroplasty was performed with both types of vagotomy so that once again the only difference between the two groups was the presence or absence of antral innervation.

TECHNIQUE OF OPERATION

The technique of proximal gastric vagotomy used in this trial has been described previously (Clarke, Allan, and Williams, 1972a). In all patients the 
operation began with a proximal gastric vagotomy and duodenal stenosis was excluded by finger palpation via a $4 \mathrm{~cm}$ gastrotomy in the body of the stomach. The type of vagotomy was then randomly selected. If a proximal gastric vagotomy was selected, the operation was concluded by confirming that the vagal nerve supply to the antrum was intact. Modified electrodes from a Burge vagotomy stimulator (Burge and Vane, 1958) were applied to the main vagal trunks at the hiatus and stimulation resulted in visible antral contractions (atropine abolishes this response and is avoided in premedication). If a selective vagotomy was selected the left gastric bundle, including the nerves of Latarjet (Latarjet, Cluzet, and Wertheimer, 1921), was divided close to the antrum.

The last 20 patients in the trial had a 3 to $4 \mathrm{~cm}$ Weinberg (1964) pyloroplasty.

\section{GASTRIC EMPTYING TESTS}

The pattern of gastric emptying of a fluid 'meal' was assessed before operation and between three and four months after operation. With the patient fasted for 12 hours a $12 \mathrm{~F}$ nasogastric tube with a radioopaque line was passed into the stomach. The tube was positioned radiographically to ensure that the tip of the tube was in the body of the stomach just proximal to the antrum and that the tube was not coiled. Residual gastric contents were aspirated and measured; the stomach was then washed out with water until the washings were clear.

The patient drank $750 \mathrm{ml}$ of $10 \%$ dextrose solution as rapidly as possible (within four minutes) and remained seated until the completion of the test. The volume of the gastric contents were assessed by a double sampling dye dilution technique (George, 1968 ) at 10-minute intervals for the first 100 minutes and thereafter at 20-minute intervals until the volume of the gastric contents had fallen to $20 \mathrm{ml}$. Phenol red was chosen as the dye as it is minimally absorbed or adsorbed in the stomach (Clarke and Williams, 1971).

For ease in estimating the concentration of the dye in the gastric aspirate the concentrated stock solution of phenol red contained $50 \mathrm{ppm}$ and approximately $100 \mu \mathrm{Ci}$ per litre of radioactive phenol red (phenol red $\mathbf{S}^{35}$ ). The concentration of phenol red in the samples of gastric aspirate and in the concentrated stock solution were then determined by liquid scintillation counting. Samples of the gastric aspirate or the stock solution, each of $0.2 \mathrm{ml}$, the latter diluted 1:10 for the analysis to prevent 'quenching', were placed in glass vials and mixed with $4.5 \mathrm{ml}$ of 2-methoxyethanol and $10 \mathrm{ml}$ of toluene containing $6 \mathrm{~g}$ per litre of butyl PBD. The vials were then counted for 10 minutes in an automated liquid scintillation counter at $2 \cdot 3$ attenuation with a vindow opening of 50 to 1000 . The counts obtained were used directly in the formula of George (1968) to determine the gastric volumes. The complete emptying pattern for each patient was then asceriained by plotting the gastric volumes against time. To enable a statistical comparison to be made between the patterns of gastric emptying two criteria were taken for comparison; the initial emptying time and the final emptying time. 'The initial emptying time' was the time taken by the stomach to empty half the volume of the dextrose 'meal'. 'The final emptying time' was the time taken for the volume of fluid in the stomach to fall to $20 \mathrm{ml}$.

\section{Results}

PREOPERATIVE GASTRIC EMPTYING

A similar preoperative pattern of gastric emptying is found for all patients in the trial. The $\mathbf{4 0}$ gastric emptying patterns have been superimposed in fig. 1 by charting all the estimations of gastric volume at each sampling interval. The two highest and two lowest estimations of gastric volume at each sampling interval are in the stippled areas and the other 36 gastric volume estimations at each sampling interval are in the hatched area.

The average gastric emptying pattern for the $\mathbf{4 0}$ patients is also shown. The average initial emptying time for the 40 patients is 69 minutes (range 34 to $124 \mathrm{~min}$ ) and the average final emptying time is 168 minutes (range 90 to 220 minutes).

The average initial emptying time ( \pm SEM $)$ and the average final emptying time ( \pm SEM) have been calculated for the 10 patients in each of the four operation groups and the statistical differences between the groups assessed by Student's $t$ test (table I).

The only significant difference in preoperative gastric emptying is between the patients in whom a proximal gastric vagotomy without pyloroplasty was later performed and the patients in whom a selective vagotomy with pyloroplasty was later performed. The initial emptying times $(P<0.025)$ and the final emptying tımes ( $P$ just $<0.05$ ) are significantly longer in the latter group of patients.

None of the 40 patients had gastric food residue present preoperatively after the overnight fast.

POSTOPERATIVE GASTRIC EMPTYING

The pattern of gastric emptying is considerably altered by operation in all four groups of patients. In only two patients is the emptying pattern after operation the same as it was preoperatively; both of these patients had a proximal gastric vagotomy without pyloroplasty performed. The changes in the 


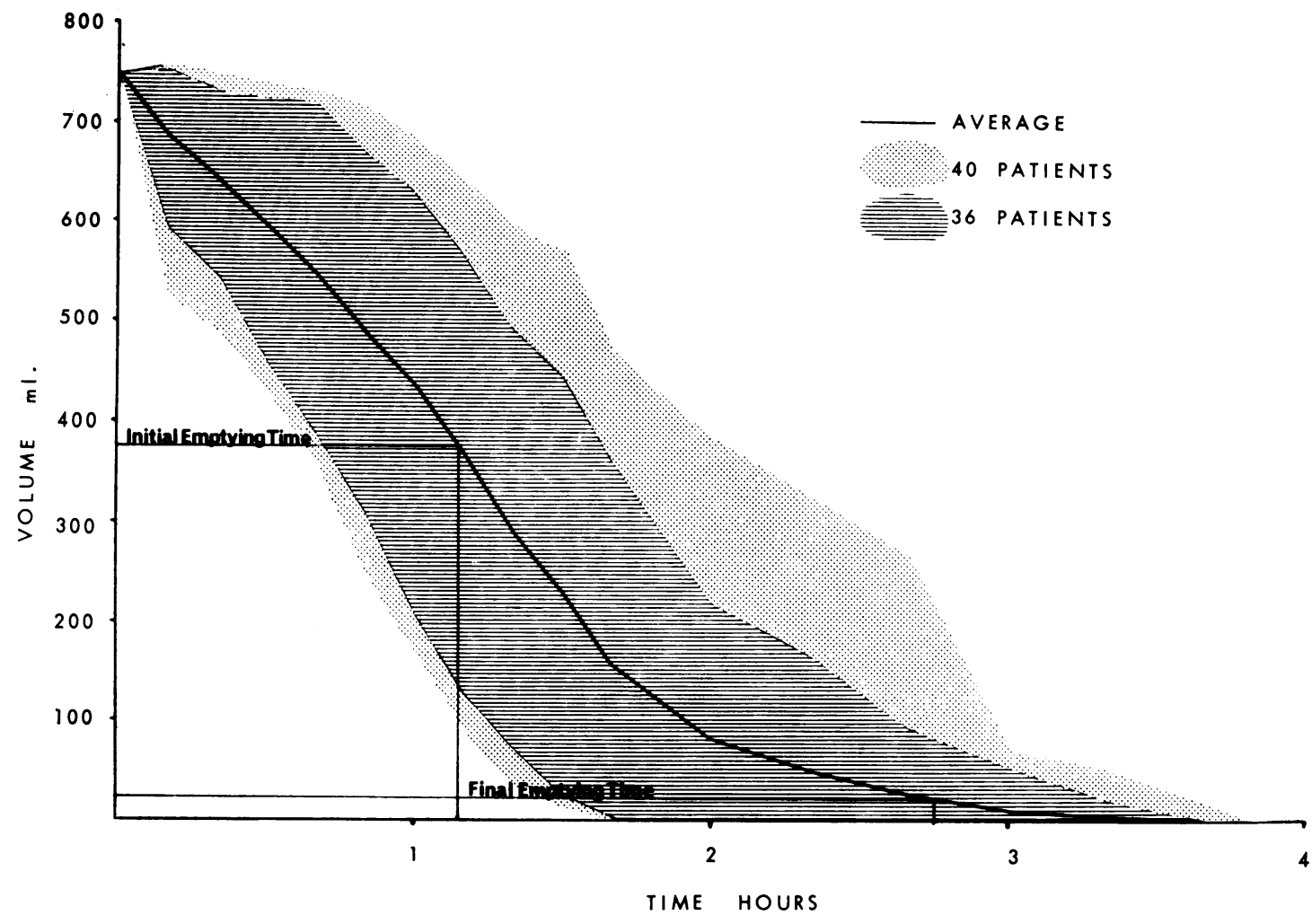

Fig. 1 The results of the tests of the rate of gastric emptying of a $10 \%$ dextrose fluid meal.

The average initial gastric emptying time is shown as the time taken for the volume of fluid in the stomach to reduce to $375 \mathrm{ml}$ and the average final emptying time is that taken for the fluid in the stomach to reduce to $20 \mathrm{ml}$.

\begin{tabular}{llc}
\hline Operation & \multicolumn{2}{l}{ Emptying Time $(\min \pm$ SEM $)$} \\
\cline { 2 - 3 } & Initial & Final \\
\hline $\begin{array}{l}\text { Selective vagotomy } \\
\begin{array}{l}\text { Proximal gastric } \\
\text { vagotomy }\end{array}\end{array}$ & $69 \pm 7 \cdot 9$ & $157 \pm 16 \cdot 2$ \\
$\begin{array}{l}\text { Selective vagotomy } \\
\text { pyloroplasty }\end{array}$ & $80 \pm 5 \cdot 7$ & $133 \pm 7 \cdot 5$ \\
$\begin{array}{c}\text { Proximal gastric } \\
\text { vagotomy }+ \\
\text { pyloroplasty }\end{array}$ & $66 \pm 5 \cdot 2$ & $162 \pm 10 \cdot 7$ \\
\hline
\end{tabular}

Table I Preoperative average initial and final emptying times pattern of gastric emptying will be discussed for each group in turn and a comparison made between the pre- and postoperative gastric emptying times on the Student's paired $t$ test.

Selective vagotomy without pyloroplasty

The initial empyting times tend to be shorter following operation. However, one patient has gross prolongation of his initial emptying time associated with gastric retention. The reduction in the initial emptying times in this group is only significant $(P<0.005)$ if this one patient is excluded from the

\begin{tabular}{|c|c|c|}
\hline \multirow[t]{2}{*}{ Operation } & \multicolumn{2}{|c|}{ Emptying Time (min) } \\
\hline & Initial & Final \\
\hline $\begin{array}{l}\text { Selective and proximal gastric vagotomies } \\
\text { Selective and selective vagotomies }+ \text { pyloroplasty } \\
\text { Selective vagotomy and proximal gastric vagotomy }+ \text { pyloroplasty } \\
\text { Proximal gastric vagotomy and selective vagotomy }+ \text { pyloroplasty } \\
\text { Proximal gastric vagotomy and proximal gastric vagotomy }+ \text { pyloroplasty } \\
\text { Selective vagotomy }+ \text { pyloroplasty and proximal gastric vagotomy }+ \text { pyloroplasty }\end{array}$ & $\begin{array}{l}\mathbf{P}>0.3 \\
\mathbf{P}>0.2 \\
\mathbf{P}>0.7 \\
\mathbf{P}>0.025^{1} \\
\mathbf{P}>0.4 \\
\mathbf{P}>0.05\end{array}$ & $\begin{array}{l}P>0.2 \\
P>0.7 \\
P>0.6 \\
P<0.05^{1} \\
P>0.3 \\
P>0.3\end{array}$ \\
\hline
\end{tabular}

Table Ia Statistical difference between operations 
analysis; if the initial emptying times of all patients in this group arc considered, then the average reduction in the initial emptying times from 69 min before operation to $40 \mathrm{~min}$ after operation is not signifi- cant $(P>0 \cdot 2)$ (fig. 2).

The final emptying times are all prolonged after this operation. The average increase in the final emptying times from $157 \mathrm{~min}$ to over $260 \mathrm{~min}$ post-

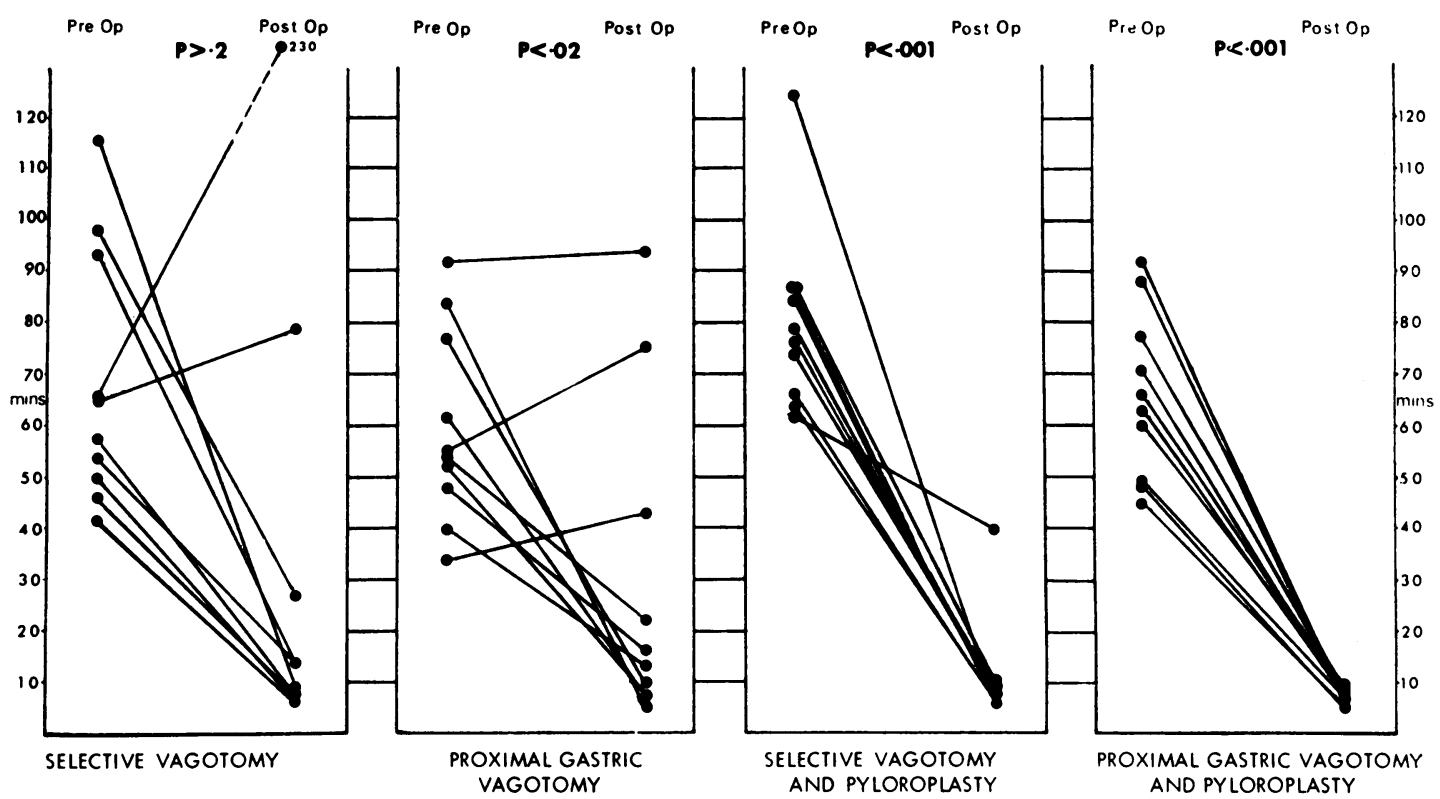

Fig. 2 Graphs showing the effects of the four different operations on the initial gastric emptying time. The significance ( $\mathrm{P}$ values) of the difference between the pre-and postoperative levels are also shown.

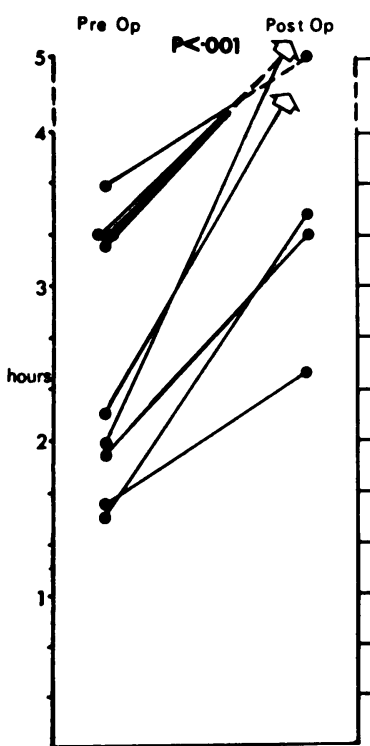

SELECTIVE VAGOTOMY

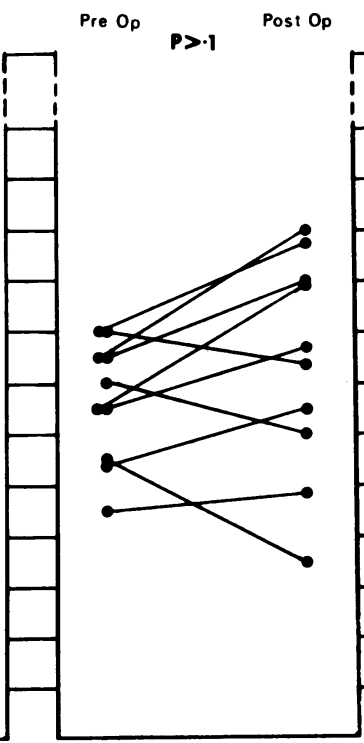

PROXIMAL GASTRIC
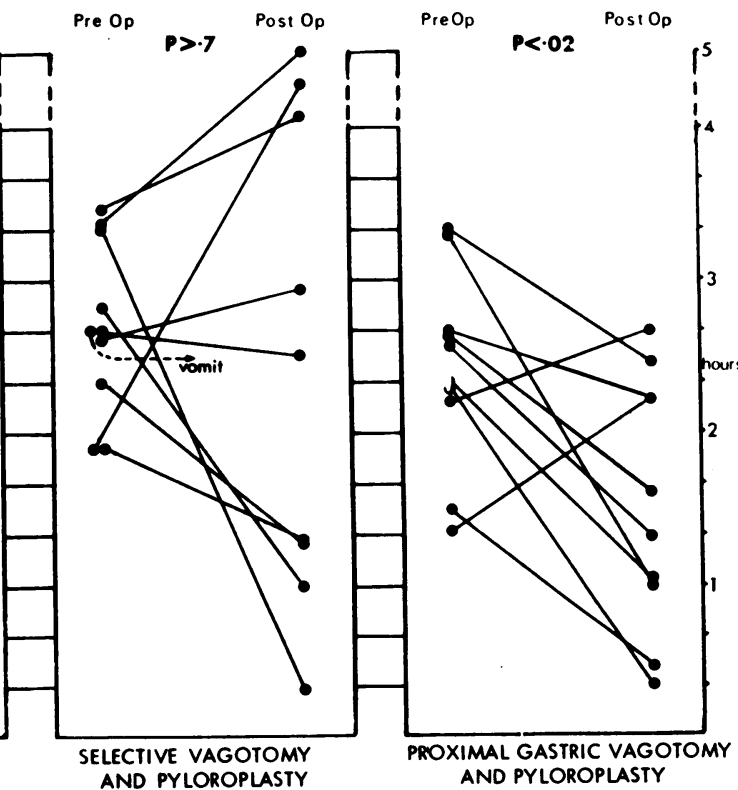

Fig. 3 Graphs showing the effects of the four different operations on the final gastric emptying time. The significance ( $\mathrm{P}$ values) of the difference between the pre-and postoperative levels are also shown. 
operatively is highly significant $(\mathrm{P}<0.001)$ (fig. 3). The stomachs of six patients had not emptied by the end of the gastric emptying test at five hours. The volume of the dextrose 'meal' remaining in the stomach at five hours varied from $25 \mathrm{ml}$ to $175 \mathrm{ml}$. The patient with the greatest degree of gastric retention had the gastric emptying test repeated six months after operation when the five-hour gastric residue had fallen from $175 \mathrm{ml}$ to $80 \mathrm{ml}$. The average emptying pattern before and after this operation is shown in the top diagram of fig. 4 and illustrates the tendency for more rapid initial emptying, the prolonged final emptying, and gastric retention.
Gastric food residue was present in all patients in this group before the start of the gastric emptying tests.

\section{Proximal gastric vagotomy without pyloroplasty}

In seven patients the initial emptying times are shortened by the operation, but three patients have similar initial emptying times before and after operation. The average reduction in the initial emptying times from $59 \mathrm{~min}$ to $29 \mathrm{~min}$ is significant $(\mathrm{P}<0.02)$ (fig. 2). The average final emptying times are not altered by this operation. The change from $133 \mathrm{~min}$ before operation to $147 \mathrm{~min}$ after operation
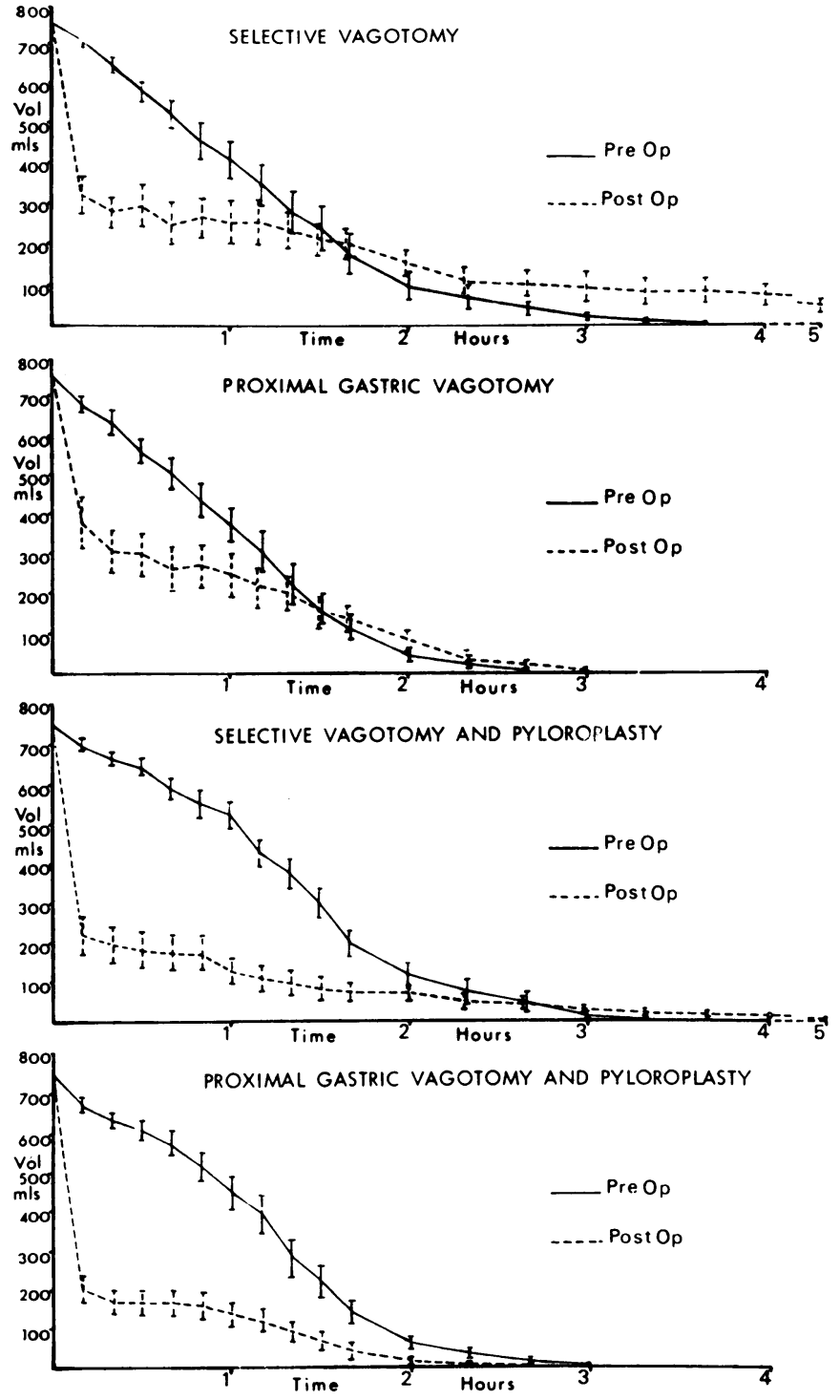

Fig. 4 Graphs showing the mean values of the gastric emptying tests $( \pm$ standard error) before and after the four different operations. 
is not significant $(P>0 \cdot 1)$ (fig. 3). The average emptying pattern before and after operation is shown in figure 4.

No patient in this group had gastric food residue present before the start of the gastric emptying test.

\section{Selective vagotomy with pyloroplasty}

The initial empyting times are all considerably shortened by this operation. The average reduction in the initial emptying times from $80 \mathrm{~min}$ to $10 \mathrm{~min}$ is highly significant $(P<0.001)$ (fig. 2). The final emptying times show marked variation after operation, the final emptying times ranging from 19 to 300 mins. Unfortunately one patient vomited the dextrose 'meal' on the two occasions it was attempted after operation, and although estimations of the volume were made up to 40 minutes, a final emptying time was not obtained. The average reduction in the final emptying times from $162 \mathrm{~min}$ to $153 \mathrm{~min}$ is not significant $(P>0.7)$ (fig. 3). The average gastric emptying pattern before and after operation is shown in fig. 4 and illustrates the rapid initial emptying and the tendency for final gastric emptying to be prolonged in some patients.

Two patients with a prolongation of their gastric emptying times had a little gastric food residue present before the start of the gastric emptying test, but there was no gastric food residue in the other eight patients.

Proximal gastric vagotomy with pyloroplasty

The initial emptying times for patients in this group are all considerably shortened by operation to 10 min or less. The average reduction in the initial emptying times from $66 \mathrm{~min}$ to $7 \mathrm{~min}$ is highly significant $(P<0.001)$ (fig. 2). The final emptying times are shortened by operation in eight of the 10 patients. The average reduction in the final emptying times from $147 \mathrm{~min}$ to $100 \mathrm{~min}$ is significant $(\mathrm{P}<0.02)$ (fig. 3). The average emptying pattern before and after operation is shown in figure 4.

No patient in this group had any gastric food residue before the start of the gastric emptying test.
COMPARISONS BETWEEN EMPTYING TESTS

AFTER DIFFERENT OPERATIONS

The comparison between the four different operation groups has been made using Student's unpaired $t$ test (table II).

\section{Initial emptying times}

Proximal gastric vagotomy with a pyloroplasty is followed by a significant reduction of initial emptying times compared with proximal gastric vagotomy without a pyloroplasty.

\section{FINAL EMPTYING TIMES}

Selective vagotomy without pyloroplasty results in a significant lengthening of final emptying times when compared with the final emptying times after any of the other three operations. Proximal gastric vagotomy with a pyloroplasty is followed by a significant reduction in final emptying times compared with proximal gastric vagotomy without a pyloroplasty.

\section{DUMPING AND THE GASTRIC EMPTYING}

TESTS

During the gastric emptying tests a careful record was kept of any 'dumping' or any diarrhoea that occurred during or soon after the tests. It was considered likely that the hypertonic dextrose 'meal' would induce 'dumping' during the gastric emptying tests, as Fenger (1965) and Hinshaw, Thompson, and

\begin{tabular}{|c|c|c|}
\hline \multirow[t]{2}{*}{ Operation } & \multicolumn{2}{|c|}{ Emptying Time $(\min \pm S E M)$} \\
\hline & Initial & Final \\
\hline $\begin{array}{l}\text { Selective vagotomy } \\
\text { Proximal gastric } \\
\text { vagotomy }\end{array}$ & $\begin{array}{l}40 \pm 22 \cdot 2 \\
29 \pm 10\end{array}$ & $\begin{array}{l}260 \text { (plus) } \pm 18.0 \\
147 \pm 13.6\end{array}$ \\
\hline $\begin{array}{l}\text { Selective vagotomy } \\
\text { + pyloroplasty }\end{array}$ & $10 \pm 3 \cdot 3$ & $153 \pm 33 \cdot 8$ \\
\hline $\begin{array}{c}\text { Proximal gastric } \\
\text { vagotomy }+ \\
\text { pyloroplasty }\end{array}$ & $7 \pm 0 \cdot 5$ & $100 \pm 13 \cdot 6$ \\
\hline
\end{tabular}

Table II Postoperative average initial and final emptying times

\begin{tabular}{|c|c|c|}
\hline \multirow[t]{2}{*}{ Operation } & \multicolumn{2}{|c|}{ Emptying Time (min) } \\
\hline & Initial & Final \\
\hline
\end{tabular}

Table IIa Statistical difference between operations 
Branson (1971) were able to produce 'dumping' in susceptible individuals by this means.

Preoperatively no 'dumping' or diarrhoea or nausea was produced by the tests.

Postoperatively eight patients developed 'dumping' during the gastric emptying tests and seven patients developed diarrhoea during or soon after the tests; in six of these seven patients the diarrhoea followed 'dumping' and in this context was clearly part of the 'dumping' syndrome. The diarrhoea occurred from $35 \mathrm{~min}$ to $120 \mathrm{~min}$ after the start of the test and was usually accompanied by extreme urgency with profuse watery diarrhoea. Five of the patients with 'dumping' and one other patient without 'dumping' vomited the dextrose 'meal' and the test had to be repeated. Other symptoms noted as part of the 'dumping' syndrome during these tests were abdominal fullness, a sensation of warmth, palpitations, sweating, weakness, faintness, and abdominal cramps. All these eight patients had, on direct questioning, suffered from varying degrees of 'dumping' since the operation, particularly with sweet drinks such as sugary tea.

What influence did the type of vagotomy and the presence or absence of a pyloroplasty play in the incidence of 'dumping'? Only one patient (following selective vagotomy) developed 'dumping' without a pyloroplasty, while in the remaining seven patients the operation included a pyloroplasty (four selective and three proximal gastric vagotomies). The difference in the incidence of 'dumping' (as described above) between the patients without a pyloroplasty (one of 20 ) and the patients with a pyloroplasty (seven of 20) is significant $(P<0.025)$.

The postoperative initial gastric emptying times for those patients with 'dumping' have been compared with the initial emptying tımes of the patients without 'dumping'. The initial emptying time (230 min) for the patient with gross gastric retention after selective vagotomy without pyloroplasty has been excluded from this analysis as his prolonged initial emptying is so abnormal. The average initial emptying time for the eight patients with 'dumping' during the gastric emptying tests is seven min (range five to $10 \mathrm{~min}$ ) compared with the average for the remaining patients in the trial of 25 minutes. This difference is significant $(P<0.02)$.

\section{Discussion}

The normal regulation of gastric emptying is principally mediated by the antro-pyloric segment of the stomach (Hunt and Knox, 1968). Operative interference with this segment of the stomach, either by denervation or pyloroplasty, may lead to alterations in the rate of gastric emptying and to post- vagotomy sequelae. The idea of treating patients with duodenal ulceration by vagotomy without a drainage procedure is therefore attractive.

It became clear, soon after vagotomy was introduced for the treatment of duodenal ulceration, that some form of drainage procedure was required with truncal vagotomy (Dragstedt and Camp, 1947). Burge and his colleagues (1969) suggested that selective vagotomy without a drainage procedure is not followed by gastric retention if duodenal stenosis is absent as pyloric innervation is preserved via a branch of the hepatic nerves from the anterior vagus. Selective vagotomy without a drainage procedure is followed by gastric retention in dogs (Shiina and Griffith, 1969; Kilby and Griffith, 1971; Interone, Del Finado, Miller, Bombeck, and Nyhus, 1971). In man, Franksson (1948) abandoned selective vagotomy without a drainage procedure because of gastric stasis and even when duodenal stenosis has been carefully excluded gastric stasis tends to develop (De Miguel, 1970; Clarke et al, 1972b). The present results suggest that a drainage procedure is necessary with selective vagotomy.

Does proximal gastric vagotomy require a drainage procedure?

In the dog, Amdrup and Griffiths (1969) and Interone and his colleagues (1971) assessed radiologically the gastric emptying of milk and meat before and after proximal gastric vagotomy without a drainage procedure; gastric emptying was unaltered by the operation. In man, Amdrup, Johnston, and Goligher (1970) have found no gastric stasis in 110 patients treated by proximal gastric vagotomy without a drainage procedure. The present results also indicate that peservation of vagal innervation to the antrum, by proximal gastric vagotomy, allows a drainage procedure to be omitted provided duodenal stenosis is absent. However, the antral innervation must be carefully preserved as inadvertent damage to the antral nerve supply will mean that a selective vagotomy is performed and gastric stasis may develop.

What effect does a pyloroplasty have on the rate or adequacy of gastric emptying?

McKelvie (1970), Colmer (1971), Cobb, Marks, and Louw (1971), and Wilkinson and Johnston (1972) have all shown that a truncal vagotomy and pyloroplasty results in very rapid initial gastric emptying, particularly when the patient is positioned so that the gastric outflow is the most dependent part of the stomach. However, these reports do not differentiate between the effect of the vagotomy and the effect of the pyloroplasty on the change in emptying pattern following operation. The present results show that vagotomy either of the parietal cell area of the stomach or of the whole stomach usually results in 
increased rapidity of initial emptying. When a pyloroplasty is added to the vagotomy a further significant increase in the rate of gastric emptying occurs. Therefore, both a vagotomy and a pyloroplasty increase the rate of gastric emptying, the one adding to the effect of the other. Clearly, therefore, to minimize rapid gastric emptying after vagotomy operations a drainage procedure is best avoided.

What is the relationship of postoperative 'dumping' to the rate of gastric emptying and to the type of operation performed? Humphrey, Wilkinson, and Johnston (1972) used a hypertonic fluid meal to assess gastric emptying and the incidence of 'dumping' one year after truncal and selective vagotomy with pyloroplasty and proximal gastric vagotomy without a drainage procedure. Compared with a group of duodenal ulcer patients before operation, patients after truncal vagotomy and pyloroplasty emptied significantly faster while those after the other operations did not. 'Dumping' followed the test meal in significantly fewer patients after proximal gastric vagotomy than after the other operations. Our results also show that postoperative 'dumping' is associated with rapid gastric emptying and to the addition of a drainage procedure to the vagotomy.

The aim of duodenal ulcer surgery is clearly to cure the ulcer without altering the gastrointestinal physiology so that unpleasant postoperative symptoms develop.

This work was supported by grants from the Medical Research Council (JAW) and the Medical Endowment Fund of The United Birmingham Hospitals (RJC).

\section{References}

Amdrup, B. M., and Griffith, C. A. (1969). Selective vagotomy of the parietal cell mass: Part I. With preservation of the innervated antrum and pylorus. Ann. Surg., 170, 207-214.

Amdrup, E., and Jensen, H. E. (1970). Selective vagotomy of the parietal cell mass preserving innervation of the undrained antrum: a preliminary report of results in patients with duodenal ulcer. Gastroenterology, 59, 522-527.

Amdrup, E., Johnston, D., and Goligher, J. C. (1970). 110 Highly selective vagotomies without drainage (H.S.V.) for duodenal ulcer. (Abstr.). Gut, 11, 1062.

Burge, H., MacLean, C., Stedeford, R., Pinn, G., and Hollanders, D. (1969). Selective vagotomy without drainage: an interim report. Brit. med. J., 3, 690-693.

Burge, H., and Vane, J. R. (1958). Method of testing for complete nerve section during vagotomy. Brit. med. J., 1, 615-618.
Clarke, R. J., and Williams, J. A. (1971). The value of phenol red and chromic chloride as nonabsorbable gastric indicators. Gut, 12 , 389-392.

Clarke, R. J., Allan, R. N., and Williams, J. A. (1972a). The effect of retaining antral innervation on the reductions of gastric acid and pepsin secretion after vagotomy. Gut, 13, 894-899.

Clarke, R. J., McFarland, J. B., and Williams, J. A. (1972b). Gastric stasis and gastric ulcer following selective vagotomy without a drainage procedure. Brit. med. J., 1, 538-539.

Cobb, J. S., Marks, I. N., and Louw, J. H. (1971). Gastric emptying after vagotomy and pyloroplasty: relation to some postoperative sequelae. Amer. J. dig. Dis., 16, 207-215.

Colmer, M. R. (1971). Dumping after vagotomy and pyloroplasty. Ann. roy. Coll. Surg. Engl., 48, 5-6.

De Miguel, J. (1970). Efecto de la vagotomia selectiva sin drenaje sobre el vaciamiento del estómago. Cirurgía Española, 24, 121126.

Dragstedt, L. R., and Camp, E. H. (1948). Follow-up of gastric vagotomy alone in the treatment of peptic ulcer. Gastroenterology, 11, 460-465.

Fenger, H. J. (1965). The dumping syndrome and gastric emptying: with a discussion on the medical and surgical treatment. Acta chir. scand., 129, 86-95.

Franksson, C. (1948). Selective abdominal vagotomy. Acta chir. scand. 96, 409-412.

George, J. D. (1968). New clinical method for measuring the rate of gastric emptying: the double sampling test meal. Gut, 9, 237242.

Goligher, J. C., Pulvertaft, C. N., Irvin, T. T., Johnston, D., Walker, B., Hall, R. A., Willson-Pepper, J., and Matheson, T. S. (1972) Five to eight year results of truncal vagotomy and pyloroplasty for duodenal ulcer. Brit. med. J., 1, 7-13.

Hinshaw, D. B., Thompson, R. J., Jr., and Branson, B. W. (1971). Pre- and post-operative 'dumping studies' in patients with peptic ulcer. Amer. J. Surg., 122, 269-274.

Humphrey, C. S., Wilkinson, A. R., and Johnston, D. (1972). The correlation between the rate of gastric emptying and dumping and diarrhoea after truncal, selective and highly selective vagotomy. Brit. J. Surg., 59, 309.

Hunt, J. N., and Knox, M. T. (1968). Basic pattern of gastric emptying. In Handbook of Physiology, Sect. 6, The Alimentary Canal, edited by C. F. Code, Vol. 4, p. 1921. American Physiological Society, Washington, D.C.

Interone, C. V., Del Finado, J. E., Miller, B., Bombeck, C. T., and Nyhus, L. M. (1971). Parietal cell vagotomy. Studies of gastric emptying and observations of protection from histamineinduced ulcer. Arch. Surg., 102, 43-44.

Johnston, D., and Wilkinson, A. R. (1970). Highly selective vagotomy without a drainage procedure in the treatment of duodenal ulcer. Brit. J. Surg., 57, 289-296.

Kilby, J. O., and Griffith, C. A. (1971). The relationships of gastric transection and vagotomy to gastric emptying. Surgery, 69, 633636.

Latarjet, A., Cluzet, J., and Wertheimer, P. (1921). Effects de la section et de l'excitation des nerfs propres de l'estomac sur la motricite ce cet organe. C.R. Soc. Biol. (Paris), 84, 985-987.

McKelvey, S. T. D. (1970). Gastric incontinence and post-vagotomy diarrhoea. Brit. J. Surg., 57, 741-747.

Shiina, E., and Griffith, C. A. (1969). Selective and total vagotomy without drainage: a comparative study of gastric secretion and motility in dogs. Ann. Surg. 169, 326-333.

Weinberg, J. A. (1964). Pyloroplasty and vagotomy for duodenal ulcer. In Current Problems in Surgery. Year Book Medical Publishers, Chicago.

Wilkinson, A. R., and Johnston, D. (1972). Effect of truncal, selective and highly selective vagotomy in man on gastric emptying of food-and-barium. Brit. J. Surg., 59, 308. 